\title{
IN MEMORIAM: HISTÓRIA, MEMÓRIA E PÓS-MEMÓRIA NO BRASIL DE HOJE
}

\author{
In Memoriam: History, Memory and Postmemory \\ in Brazil Nowadays
}

Andréa Machado de Almeida MATTOS

Universidade Federal de Minas Gerais Pesquisadora Nível Pq2 do CNPq (Processo n. 312405/2017-0) andreamattos@ufmg.br https://orcid.org/0000-0003-3190-7329

Que seja este o nosso mote: "Não esqueçam." (Umberto Eco)

Um dia estávamos todos vivendo nossas rotinas diárias despreocupadamente. Um dia... Pandemia! Fomos todos pegos de surpresa... Justamente quando o Brasil passava por uma total transformação social e política, desde as eleições de 2018, em que Jair Bolsonaro fora eleito. Não estávamos preparados... “Ah, mas quem estava preparado?”, você há de perguntar. Ou ainda "Como poderíamos estar preparados?" A pandemia do novo Corona vírus - ou COVID-19, como a nova doença passou a ser chamada - foi inicialmente detectada na cidade de Wuhan, na China, em dezembro de 2019 e rapidamente se espalhou pelo mundo, chegando ao Brasil no fim de fevereiro de 2020, segundo informações oficiais. Alguns países foram atingidos primeiro e de forma mais dura, como a Itália e a própria China, e tomaram medidas para tentar evitar as incontáveis mortes de seus cidadãos contaminados. Sim, o Brasil teve tempo para se preparar e poderia ter aprendido com o exemplo dos países que foram atingidos anteriormente. Mas não nos preparamos...

O novo governo fez pouco caso da pandemia. Chegou a dizer que era apenas uma gripezinha... Demoramos a começar a nos preparar, demoramos a tomar medidas de isolamento social e nossos órgãos de saúde nacionais, estaduais e municipais tomavam decisões contraditórias entre si e muitas vezes davam instruções errôneas e desconexas à população. O novo governo recusava-se a seguir as orientações da Organização Mundial 
da Saúde (OMS) e se desentendia com seu próprio Ministério da Saúde, que trocou de ministro duas vezes durante o início da pandemia. O resultado ainda está em andamento. Escrevo em fins de julho de 2020 e os efeitos da pandemia de COVID-19 no Brasil são devastadores - a trégua não parece estar próxima!

Como uma premonição, ou quem sabe rememoração de outras pestes já vividas pela humanidade, Dostoiévski descreve com precisão a situação que vivemos hoje mundialmente: pandemia e polarização política. Em Crime e Castigo, publicado pela primeira vez em 1866, o autor relata os sonhos do protagonista enquanto estivera doente:

\begin{abstract}
Imaginava, doente, que o mundo inteiro era fadado a perecer de uma peste terrível, nunca vista nem suposta, que vinha do fundo da Ásia para a Europa. Toda a humanidade ia morrer, à exceção de algumas pessoas eleitas, bem poucas. Surgiram certas triquinas novas, entes microscópicos que invadiam o corpo humano. Mas esses entes eram espíritos dotados de inteligência e de vontade. As pessoas acometidas por eles ficavam logo possessas e insanas. Mas nunca, nunca as pessoas se consideravam tão sábias e invencíveis em sua sabedoria quanto as infectadas. Nunca achavam tão inabaláveis suas sentenças, suas conclusões científicas, suas convicções morais e suas crenças. Vilas inteiras, cidades inteiras, povos inteiros infectavam-se e enlouqueciam. Todos estavam transtornados e não se entendiam; cada um pensava que a verdade só cabia a si, e afligia-se de olhar para os outros, batia-se no peito, chorava e torcia os braços. As pessoas não sabiam como e a quem julgar nem concordavam entre si sobre em que consistiam o mal e o bem; ignoravam a quem acusar e a quem absolver. Matavam umas às outras numa fúria absurda. [...]. Surgiram incêndios, veio a fome. Tudo e todos pereciam. A peste se alastrava e avançava cada vez mais. Só algumas pessoas é que poderiam salvar-se no mundo inteiro [...] (DOSTOIÉVSKI, 2019, p. 573-574).
\end{abstract}

Um dos efeitos mais óbvios da pandemia é que as consequências são piores para as populações marginalizadas e grupos minoritarizados: pobres, negros, mulheres... mulheres negras... O Sistema Único de Saúde (SUS) brasileiro entra em colapso em muitas cidades... As vidas perdidas se multiplicam... Somam milhares! O atual governo brasileiro não se importa... "Gripezinha! Alguns vão morrer! O que que eu posso fazer? Não sou coveiro!" Palavras de um presidente eleito - inacreditavelmente eleito!!

Em 1995, num evento promovido pelos departamentos de italiano e francês da Universidade Columbia, nos Estados Unidos (EUA), Umberto Eco descreveu o que chamou de "Fascismo Eterno". A publicação desse texto (ECO, 2020) chegou em minhas 
mãos por acaso, como um presente. Nesse texto, rememorando sua infância vivida durante a Segunda Guerra Mundial, o autor afirma que o fascismo "ainda está ao nosso redor, às vezes em trajes civis" (ECO, 2020, p. 60). Embora para Umberto Eco o fascismo apresente características militares, pode também surgir em outras vestes...

Essa tem sido a experiência dos brasileiros desde a eleição de Bolsonaro em 2018. Os discursos fascistas, legitimados pelo presidente eleito, se multiplicam, se revelam desavergonhadamente... Ensaiam várias das características citadas por Eco como características de governos fascistas: tradicionalismo; rejeição da modernidade, da cultura e da ciência; apelo às classes médias; populismo; nacionalismo; antipacifismo; elitismo; hierarquia baseada em modelo militar; machismo; intolerância e culto da morte. Humberto Eco (2020, p. 54) afirma que o herói fascista "espera impacientemente pela morte". E continua: "Note-se, porém, que sua impaciência provoca com maior frequência a morte dos outros" (ECO, 2020, p. 54). Curioso... parece-me familiar...

Mesmo em 1995, quando a internet ainda não era como a conhecemos atualmente, Humberto Eco parecia já prever o que passamos hoje: "Em nosso futuro, desenha-se um populismo qualitativo de TV ou internet, no qual a resposta emocional de um grupo selecionado de cidadãos pode ser apresentada e aceita como a 'voz do povo'” (ECO, 2020, p. 56-57). Sim, com certeza é familiar! Vivemos uma ditadura de poucos, justamente aqueles tradicionalistas, nacionalistas, machistas, intolerantes à diversidade! Apoiadores do atual governo travam uma guerra na internet, mais precisamente nas redes sociais, lançando a todo momento mensagens falsas que se disseminam como vírus - Corona vírus... Não pode haver paz...

As reflexões de Humberto Eco sobre o Fascismo Eterno (ECO, 2020) nos ensinam a importância de conhecer a História e de preservar a memória. A História se repete... vai e volta como numa brincadeira de criança... A História recente da humanidade está repleta de acontecimentos abomináveis. Se olharmos apenas para o século passado, podemos enumerar duas guerras mundiais, o Holocausto, as bombas atômicas, a chamada Guerra Fria, governos totalitários e Ditaduras Militares na América Latina, inclusive no Brasil, o desastre atômico de Chernobyl, a Guerra do Vietnam, e políticas genocidas em vários países do mundo, dentre tantos outros eventos atrozes e traumáticos não só para aqueles que deles participaram mas também para as gerações seguintes. Precisamos lembrar! 
Marianne Hirsch, num artigo de 1992, Family pictures: Maus, mourning, and postmemory, cunhou o termo "pós-memória" para se referir à transmissão intergeracional de experiências traumáticas vividas pela geração anterior e narradas às gerações subsequentes, tornando-se, assim, um tipo de memória. Hirsch (1992) se referia inicialmente aos descendentes de sobreviventes do Holocausto, mas o conceito de pós memória foi depois expandido para vários outros contextos de eventos traumáticos e foi também apropriado e amplamente usado em várias disciplinas. Na definição inicial de Hirsch (1992), pós-memória buscava representar a relação entre os filhos de sobreviventes do Holocausto com as memórias de seus pais. No entanto, em trabalhos mais recentes a própria autora expandiu o termo para definir "a relação que gerações posteriores ou testemunhas contemporâneas distantes mantém com o trauma pessoal, coletivo e cultural de outros - com experiências que eles 'se lembram' ou sabem somente por meio de histórias, imagens e comportamentos" (HIRSCH, 2014, p. 339, tradução minha).

Num texto de 2014, pergunto se é papel do professor de línguas trazer certos temas ditos "críticos" para discussão em sala de aula de ensino de língua estrangeira (MATTOS, 2014). Penso que sim... Recentemente, Mattos e Caetano $(2018$, 2019) trouxeram o conceito de pós-memória para a Linguística Aplicada, mais precisamente para a área de formação do professor de línguas, e defendem que o conceito

pode trazer novas possibilidades para a educação crítica de língua estrangeira e para a formação crítica de professores, em ambos os casos, visando a promover uma abordagem crítica para o currículo de ensino de línguas, especialmente em contextos de escolas públicas, com foco na educação para a cidadania e no ensino do inglês para a justiça social (MATTOS; CAETANO, 2019, p. 182).

De fato, penso que a educação linguística crítica e a formação crítica de professores devem contribuir para a preservação da memória de eventos traumáticos de nossa história visando à garantia da transmissão da memória intergeracional, ou pósmemória, como Hirsch (1992) propôs. Jorge e Ribeiro (2013) reconhecem que "é fundamental perceber a importância do ato de recordar para as diversas culturas e para a constituição de traços de identificação que concedem ao grupo a sensação de pertencimento" (JORGE; RIBEIRO, 2013, p. 12). Na visão dos autores, 
Lembrar é um ato de recuperação e de reavaliação, que pressupõe a possibilidade de interlocução crítica com o passado. Lembramos para não esquecer; como indivíduos e como sociedade, ainda que $o$ esquecimento seja a outra face da moeda a que chamamos memória. Lembramos para não errar de novo, para impedir que a opressão e a violência tornem a se manifestar de forma avassaladora e insidiosa (JORGE; RIBEIRO, 2013, p. 12).

Trazendo esses pensamentos para o Brasil de hoje, mais que nunca é preciso lembrar! Lembrar para não esquecer! Para evitar que o fascismo disfarçado de democracia se instale novamente entre nós. Como afirmou Humberto Eco,

Devemos ficar atentos para que o sentido das palavras 'liberdade' e 'ditadura' não seja esquecido de novo. [...] O fascismo pode voltar sob as vestes mais inocentes. Nosso dever é desmascará-lo e apontar o dedo par cada uma de suas novas formas - a cada dia, em cada lugar do mundo. Liberdade e libertação são uma tarefa que não acaba nunca. Que seja este o nosso mote: 'não esqueçam' (ECO, 2020, p. 60-61).

Bem, este deveria ser um artigo de opinião. Olhando agora para o texto já escrito, parece mais um artigo de reflexão, de pensamentos aleatórios... não tenho opinião formada sobre muitos dos tópicos aqui abordados. Mas tenho memória... Só a memória pode, de fato, nos possibilitar escrever e contar uma outra história.

Um dia...

\section{AGRADECIMENTOS}

Agradeço a Galileu Menezes, meu esposo, por ter chamado minha atenção para o trecho do clássico de Dostoiéviski aqui citado (DOSTOIÉVSKI, 2019, p. 573-574). Agradeço também por ter me presenteado com o livro de Humberto Eco que menciono neste trabalho. Agradeço, ainda, à Prof. a Dra. Leina Jucá por suas contribuições à versão inicial deste texto.

\section{REFERÊNCIAS}

DOSTOIÉVSKI, F. Crime e castigo. Tradução de Oleg Almeida. São Paulo:Martin Claret, 2019. 
ECO, H. O fascismo eterno. Tradução de Eliane Aguiar. 6 ed., Rio de Janeiro: Record, 2020.

HIRSCH, M. Family pictures: Maus, mourning, and post-memory. Discourse, v.15, n.2, p.3-29, Winter, 1992-93. Disponível em: <https://www.jstor.org/stable/41389264?seq=1>. Acesso em: 2 ago. 2020.

HIRSCH, M. Connective histories in vulnerable times (MLA Presidential Address). Publications of the Modern Language Association of America (PMLA), v.129, n.3, p.330348, 2014. D.O.I.: <https://doi.org/10.1632/pmla.2014.129.3.330>. Acesso em: 12 set. 2020.

JORGE, S. R.; RIBEIRO, M. C. Apresentação. Revista Abril, v.5, n.11, p.9-12, jul./dez. 2013. Disponível em: <https://periodicos.uff.br/revistaabril/issue/view/1598/showToc>. Acesso em: 12 set. 2020.

MATTOS, A. M. A. Educating language teachers for social justice teaching. Interfaces Brasil/Canadá, v.14, n.2, p.125-151, 2014. Disponível em: $<$ https://periodicos.ufpel.edu.br/ojs2/index.php/interfaces/article/view/6738/4644>.

Acesso em: 06 jan. 2015.

MATTOS, A. M. A.; CAETANO, E. A. Memory, postmemory and critical language teacher education. Analecta Política, v.8, n.15, p.235-254, 2018. D.O.I.: <http://dx.doi.org/10.18566/apolit.v8n15.a04>. Acesso em: 12 set. 2020.

MATTOS, A. M. A.; CAETANO, E. A. Memória, pós-memória e formação crítica de professores de línguas. Línguas \& Letras, v.20, n.46, p.167-186, 2019. Disponível em: $<$ http://e-revista.unioeste.br/index.php/linguaseletras/article/view/21611>. Acesso em: 12 set. 2020. 